\title{
Digestibilidade aparente e verdadeira do fósforo de alimentos de origem animal para suínos
}

\author{
[Apparent and true digestibility of phosphorus from animal \\ origin feedstuffs for swines] \\ S. Bünzen ${ }^{1}$, H.S. Rostagno ${ }^{2}$, D.C. Lopes $^{2}$, P.C. Gomes ${ }^{2}$, F.A.M. Hashimoto ${ }^{3}$, \\ L.R. Apolonio ${ }^{3}$, C.G. Borsatto \\ ${ }^{1}$ Aluno de pós-graduação - UFV - Viçosa, MG \\ ${ }^{2}$ Universidade Federal de Viçosa - Viçosa, MG \\ ${ }^{3}$ Zootecnista autônomo \\ ${ }^{4}$ Aluno de graduação - UFV - Viçosa, MG
}

\begin{abstract}
RESUMO
Determinaram-se os coeficientes de digestibilidade aparente (CDAP) e verdadeira (CDVP) do fósforo de alimentos de origem animal. Foram utilizados 24 suínos, machos castrados, com média de peso de $25,0 \pm 3,0 \mathrm{~kg}$ no período de crescimento e 24 suínos com média de peso de $60,0 \pm 5,0 \mathrm{~kg}$ para o período de terminação. Os tratamentos foram resultantes de um fatorial de duas metodologias (coleta total de fezes e indicador fecal), duas fases (crescimento e terminação) e oito dietas (seis alimentos de origem animal, uma ração referência e uma ração com baixo conteúdo de fósforo total para estimar as perdas de fósforo endógeno), com três repetições e um animal por unidade experimental. Não foram encontradas diferenças entre as metodologias ou entre as fases avaliadas $(\mathrm{P}>0,05)$. Os valores médios de CDAP e CDVP encontrados com suínos em crescimento e terminação foram, respectivamente, 61,7 e $62,0 \%$ para a farinha de carne e ossos com 35\% de proteína bruta (PB); 62,3 e $62,9 \%$ para a farinha de carne e ossos com $41 \%$ de PB; 49,0 e $52,5 \%$ para a farinha de vísceras e penas; 72,3 e $90,8 \%$ para a farinha de penas; 85,5 e $88,5 \%$ para a farinha de peixe com $55 \%$ de $\mathrm{PB}$; e 80,0 e $92,0 \%$ para o soro de leite em pó.
\end{abstract}

Palavras-chave: suíno, coleta total de fezes, fósforo digestível, óxido crômico

\begin{abstract}
The coefficients of apparent (CADP) and true (CTDP) digestibility of the phosphorus from animal origin feedstuffs were determined. Twenty-four barrows in growing phase with initial weight $25.0 \pm 3.0 \mathrm{~kg}$ and the same barrows in finishing phase with initial weight $60.0 \pm 5.0 \mathrm{~kg}$ were used. The treatments were made by a factorial of two methodologies (total collection of feces and fecal marker), two phases (growing and finishing), and eight diets (six animal origin feedstuffs, one reference diet, and one diet with low content of total phosphorus in order to estimate the losses of endogenous phosphorus), with three replicates by treatment. There was no difference between the methodologies or phases evaluated (P>0.05). The average of CADP and CTDP found in growing and finishing phases were, respectively, 61.7 and $62.0 \%$ for $35 \%$ crude protein (CP) meat and bone meal; 62.3 and $62.9 \%$ for $41 \%$ CP meat and bone meal; 49.0 and $52.5 \%$ for feather and poultry by-products meal; 72.3 and $90.8 \%$ for feather meal; 85.5 and $88.5 \%$ for $55 \%$ CP fish meal; and 80.0 and $92.0 \%$ for powder milk whey.
\end{abstract}

Keywords: swine, chromic oxide, digestible phosphorus, total fecal collection

Recebido em 18 de agosto de 2008

Aceito em 25 de maio de 2009

E-mail: sbunzen@gmail.com 


\section{INTRODUÇÃO}

A inclusão de alimentos alternativos nas dietas para suínos tem sido uma constante e visa, não somente à diminuição de custos, mas também ao aproveitamento de matéria prima considerada como resíduos.

Os produtos de origem animal, como farinha de carne e ossos e farinhas de resíduos de abatedouros adquirem caráter relevante pelo fato de serem produzidos em grande quantidade. Sua utilização como fonte proteica e de minerais pode ser de grande valia se respeitadas normas de fabricação e utilização na alimentação de animais monogástricos, especialmente para suínos. Além disso, a presença de ossos nestes alimentos o torna boa fonte de minerais, particularmente de fósforo, com grande biodisponibilidade para os animais (Traylor et al., 2005).

O fósforo é um mineral essencial, por desempenhar importantes funções nos processos metabólicos, sendo necessária a adição de fontes de fósforo inorgânico nas rações para suínos (Moreira et al., 2004), uma vez que os alimentos de origem vegetal possuem a maior parte do fósforo na forma não disponível para os monogástricos, complexado como fitato. A suplementação de fósforo com fontes inorgânicas na forma de fosfatos acaba por que elevar ainda mais os custos da ração (Bünzen et al., 2008).

A utilização de produtos de origem animal nas dietas para suínos, formuladas com base no conteúdo de fósforo digestível em lugar do fósforo total, assim como ocorre na formulação com base em aminoácidos digestíveis, maximiza a utilização do fósforo na ração, reduzindo as necessidades de suplementação com outras fontes minerais e também os excessos de fósforo não absorvido que acabam por ser excretados nas fezes, contribuindo fortemente para a poluição do solo e dos mananciais de água.

Dessa forma, este trabalho foi realizado com o objetivo de determinar os coeficientes de digestibilidade aparente e verdadeira do fósforo de alguns alimentos de origem animal, comumente utilizados nas formulações de rações para suínos.

\section{MATERIAL E MÉTODOS}

Foram utilizados 24 suínos, machos castrados, com peso médio inicial de $25,0 \pm 3,0 \mathrm{~kg}$ na fase de crescimento e 24 suínos com peso médio de $60,0 \pm 5,0 \mathrm{~kg}$ para a fase de terminação. Os animais foram alojados, individualmente, em gaiolas de metabolismo semelhantes às descritas por Pekas (1968), onde permaneceram por 12 dias, sendo sete de adaptação às gaiolas e às rações experimentais, e cinco dias de coleta de fezes e urina.

O delineamento experimental utilizado foi $\mathrm{o}$ inteiramente ao acaso, em arranjo fatorial de duas metodologias (coleta total de fezes e indicador fecal - óxido crômico $\left(\mathrm{Cr}_{2} \mathrm{O}_{3}\right)$, utilizadas simultaneamente), duas fases (crescimento e terminação) e oito dietas (seis alimentos de origem animal, uma ração referência e uma ração com baixo conteúdo de fósforo total para estimar as perdas de fósforo endógeno), com três repetições e um animal por unidade experimental.

Os tratamentos consistiram de seis alimentos de origem animal, uma ração referência, suplementada com aminoácidos sintéticos e contendo $0,17 \%$ de $\mathrm{P}$ total, de modo a atender as exigências dos animais segundo Rostagno et al. (2000), exceto para fósforo e uma dieta com baixo conteúdo de fósforo $(0,03 \%)$, utilizada para estimar as perdas de fósforo endógeno excretado nas fezes (Tab. 1).

Os alimentos avaliados substituíram a ração referência, em quantidades variadas, de modo que cada um fornecesse $0,15 \%$ de $\mathrm{P}$ total, com exceção das farinhas de carne e ossos, que forneceram $0,20 \%$ de fósforo total, devido ao maior conteúdo desse mineral nesses alimentos. A percentagem de substituição da ração referência pelos alimentos foi: farinha de carne e osso com $35 \%$ de proteína bruta (PB) $(2,67)$, farinha de carne e ossos com $41 \%$ de PB $(3,23)$, farinha de penas e vísceras de aves $(14,71)$, farinha de penas $(22,39)$, farinha de peixe $(3,96)$ e soro de leite em pó $(21,13)$. A cada dieta foi adicionado $0,5 \%$ de óxido crômico $\left(\mathrm{Cr}_{2} \mathrm{O}_{3}\right)$ como indicador fecal, em substituição ao inerte. 
Tabela 1. Composições centesimais da ração referência e ração baixo fósforo utilizadas no experimento nas fases de crescimento e terminação de suínos

\begin{tabular}{|c|c|c|}
\hline Ingrediente & $\begin{array}{c}\text { Ração referência } \\
(\%)\end{array}$ & $\begin{array}{c}\text { Ração baixo fósforo } \\
(\%)\end{array}$ \\
\hline Milho & 40,59 & - \\
\hline Farinha de milho & 20,00 & 29,90 \\
\hline Açúcar & 10,00 & 25,00 \\
\hline Amido & 10,00 & 25,00 \\
\hline Farelo de soja & 8,00 & - \\
\hline Óleo de soja & 2,80 & 4,00 \\
\hline Plasma sanguíneo & 2,73 & 7,51 \\
\hline Calcário & 2,16 & 2,50 \\
\hline Concentrado proteico de soja & 1,50 & - \\
\hline Sal comum & 0,21 & 0,09 \\
\hline Mistura mineral $^{1}$ & 0,13 & 0,13 \\
\hline Mistura vitamínica $^{2}$ & 0,06 & 0,07 \\
\hline BHT & 0,01 & 0,01 \\
\hline Inerte & $1,00^{3}$ & $4,50^{4}$ \\
\hline L-Lisina & 0,44 & 0,50 \\
\hline DL-Metionina & 0,16 & 0,48 \\
\hline L-Treonina & 0,15 & 0,24 \\
\hline L-Triptofano & 0,06 & 0,07 \\
\hline Total & 100,00 & 100,00 \\
\hline \multicolumn{3}{|c|}{ Composição calculada $^{5}$} \\
\hline Proteína bruta $(\%)$ & 12,20 & 8,79 \\
\hline Energia digestível, $\mathrm{Kcal} / \mathrm{kg}$ & 3.602 & 3.660 \\
\hline Fibra bruta $(\%)$ & 1,62 & 1,78 \\
\hline Cálcio $(\%)$ & 0,88 & 0,98 \\
\hline Fósforo total $(\%)$ & 0,17 & 0,03 \\
\hline
\end{tabular}

${ }^{\mathrm{T}}$ Composição por kg= Fe: 180g; Cu: 20g; Co: 4g; Mn: 80g; Zn: 140g; I: 4g; veículo q.s.p. 1.000g.

${ }^{2}$ Composição por $\mathrm{kg}=$ vit.A: $9.000 .000 \mathrm{UI}$; vit.D3: $1.500 .000 \mathrm{UI}$; vit.E: $10.000 \mathrm{UI}$; vit.B1: $2 \mathrm{~g}$; B2: $5 \mathrm{~g}$; vit.B6: 30g; ácido pantotênico: $25 \mathrm{~g}$; vit.K3: $4 \mathrm{~g}$; vit.B12: $40 \mathrm{mg}$; ácido nicotínico: $40 \mathrm{~g}$; selênio: $23 \mathrm{mg}$; antioxidante: $30 \mathrm{~g}$; veículo q.s.p. $1.000 \mathrm{~g}$.

${ }^{3}$ Areia lavada.

${ }^{4}$ Sabugo de milho moído.

${ }^{5}$ Valores analisados no Laboratório de Nutrição Animal do Departamento de Zootecnia da UFV.

Ração referência $(12,54 \% \mathrm{~PB}, 0,88 \% \mathrm{Ca}$ e $0,21 \% \mathrm{P})$ e ração baixo fósforo $(7,96 \% \mathrm{~PB}, 0,98 \% \mathrm{Ca}$ e $0,02 \% \mathrm{P})$.

As dietas experimentais foram fornecidas em função do peso metabólico dos animais $\left(\mathrm{kg}^{0,75}\right)$, em duas refeições diárias, às 8 e $17 \mathrm{~h}$. Água foi fornecida à vontade.

A coleta de fezes e a preparação das amostras para análises foram realizadas de acordo com Gomes et al. (1989). As análises dos teores de matéria seca, fósforo total e óxido crômico foram realizadas de acordo com as metodologias descritas por Silva e Queiroz (2004). Foram determinados o consumo de matéria seca ( $\mathrm{g} / \mathrm{dia})$, consumo de fósforo total, consumo de fósforo da ração referência e dos alimentos ( $\mathrm{g} / \mathrm{dia}$ ), fósforo fornecido pelo alimento e pela ração referência
(\%), fósforo na ração e nas fezes (\%), excreção de fósforo ( $\mathrm{g} / \mathrm{dia})$, fator de indigestibilidade $\left(\mathrm{Cr}_{2} \mathrm{O}_{3}\right)$, fator de indigestibilidade endógena e fósforo excretado pelos animais que receberam a dieta com baixo teor de fósforo (fósforo endógeno, g/dia). Os dados obtidos foram utilizados nas fórmulas descritas por Jongbloed e Kemme (1990) e Rostagno e Featherston (1977) para determinação dos coeficientes de digestibilidade aparente (CDAP) e verdadeira (CDVP) do fósforo.

Os dados obtidos foram submetidos à análise de variância seguida de teste de médias, utilizando o pacote estatístico SAEG (Sistema..., 2001). 


\section{RESULTADOS E DISCUSSÃO}

Os valores médios dos CDAP e CDVP dos alimentos avaliados, obtidos nas duas fases, encontram-se nas Tab. 2 e 3 . Não houve interação $(\mathrm{P}>0,05)$ metodologia de coleta total de fezes e indicador fecal versus alimento utilizado para determinação dos valores de CDAP dos alimentos nas fases de crescimento e terminação, indicando que ambos os métodos podem ser utilizados para essa avaliação. Resultado semelhante entre as metodologias de coleta total e indicador fecal (óxido crômico) também foram apresentados por Gomes et al. (1989), ao avaliarem a digestibilidade do fósforo em diferentes alimentos para suínos em crescimento.

Não houve efeito da idade dos animais sobre os valores dos coeficientes de digestibilidade aparente e verdadeira determinados. Dessa forma, aparentemente para os alimentos de origem animal, o fósforo inorgânico presente pode ser aproveitado de forma similar tanto para suínos em crescimento como para suínos em terminação.

O conteúdo de fósforo das fezes é proveniente de origem dietética e de perdas endógenas. Para determinação da digestibilidade verdadeira do fósforo, a fração de fósforo endógeno tem menor influência em alimentos com maior conteúdo de fósforo total, como as farinhas de origem animal. Dessa forma, não houve diferenças $(\mathrm{P}>0,05)$ entre os valores médios dos coeficientes de digestibilidade aparente e verdadeira determinados para os diferentes alimentos avaliados. Isto confirma o que foi apresentado por diversos autores, que utilizaram apenas os valores de digestibilidade aparente para determinação da utilização biológica do fósforo pelos animais (Dellaert et al., 1990; Jongbloed e Kemme, 1990), sobretudo nos alimentos com maior proporção de fósforo inorgânico.

Os valores médios de CDAP e CDVP da farinha de carne e ossos com 35\% de PB e da farinha de carne e ossos com 41\% PB apresentaram-se semelhantes, em torno de $62,0 \%$. Não houve diferenças entre as fases de crescimento $\mathrm{e}$ terminação $(\mathrm{P}>0,05)$, indicando não haver influência da idade no aproveitamento do fósforo presente nestes alimentos. Da mesma forma, os valores de CDAP e CDVP apresentaram-se similares, indicando haver pouca influência das perdas de fósforo endógeno nos alimentos de maior conteúdo de fósforo total.

Os valores médios de CDAP e CDVP obtidos para as duas farinhas avaliadas foram mais baixos que os apresentados por Jongbloed e Kemme (1998) e Sauvant et al. (2003), que encontraram 81,0 e $75,0 \%$, respectivamente, para duas diferentes farinhas de carne e ossos avaliadas com animais em crescimento e terminação. Deve-se atentar, no entanto, para a grande variação existente entre os produtos de origem animal.

Tabela 2. Coeficientes de digestibilidade aparente do fósforo de alimentos, utilizando diferentes metodologias, para suínos em crescimento e em terminação (\%)

\begin{tabular}{|c|c|c|c|c|c|c|c|}
\hline \multirow[b]{2}{*}{ Alimento } & \multicolumn{3}{|c|}{ Crescimento } & \multicolumn{3}{|c|}{ Terminação } & \multirow[b]{2}{*}{$\begin{array}{l}\text { Média } \\
\text { geral }\end{array}$} \\
\hline & $\begin{array}{c}\text { Coleta } \\
\text { total }\end{array}$ & $\begin{array}{l}\text { Indicador } \\
\text { fecal }\end{array}$ & $\mathrm{M} \pm \mathrm{EP}$ & $\begin{array}{c}\text { Coleta } \\
\text { total }\end{array}$ & $\begin{array}{l}\text { Indicador } \\
\text { fecal }\end{array}$ & $\mathrm{M} \pm \mathrm{EP}$ & \\
\hline $\begin{array}{l}\text { Farinha de carne e ossos } \\
35 \% \text { PB }(7,26)^{1}\end{array}$ & 63,84 & 65,23 & $64,53 \pm 4,77$ & 58,62 & 58,97 & $58,80 \pm 4,28$ & 61,67 \\
\hline $\begin{array}{l}\text { Farinha de carne e ossos } \\
41 \% \text { PB }(7,06)^{1}\end{array}$ & 63,98 & 57,02 & $60,50 \pm 2,94$ & 67,90 & 60,22 & $64,06 \pm 2,53$ & 62,28 \\
\hline $\begin{array}{l}\text { Farinha vísceras e penas } \\
\text { de aves }(2,07)^{1}\end{array}$ & 52,30 & 51,17 & $51,73 \pm 1,85$ & 43,67 & 48,75 & $46,21 \pm 1,89$ & 48,97 \\
\hline Farinha de penas $(0,36)^{1}$ & 61,66 & 68,43 & $65,05 \pm 5,50$ & 86,82 & 72,44 & $79,63 \pm 3,72$ & 72,34 \\
\hline $\begin{array}{l}\text { Farinha de peixes } \\
(1,77)^{1}\end{array}$ & 78,98 & 85,22 & $82,10 \pm 4,88$ & 93,61 & 84,34 & $88,98 \pm 5,45$ & 85,54 \\
\hline Soro de leite $(0,62)^{1}$ & 80,81 & 81,85 & $81,33 \pm 3,04$ & 69,46 & 87,80 & $78,63 \pm 5,10$ & 79,98 \\
\hline Média método $\pm \mathrm{EP}^{2}$ & $\begin{array}{c}66,93 \pm \\
2,29 \mathrm{a} \\
\end{array}$ & $\begin{array}{c}68,15 \pm \\
6,48 \mathrm{a} \\
\end{array}$ & & $\begin{array}{c}70,02 \pm \\
3,15 \mathrm{a}\end{array}$ & $\begin{array}{c}68,75 \pm \\
2,79 \mathrm{a} \\
\end{array}$ & & \\
\hline
\end{tabular}

Coeficiente de variação $=14,3 \%$. Médias com letras distintas na linha diferem entre si pelo teste Newman-Keul's $(\mathrm{P}>0,05)$.

$\mathrm{M} \pm \mathrm{EP}$ : Média \pm erro-padrão da média. ${ }^{1}$ Conteúdo de fósforo analisado; ${ }^{2}$ Comparação de médias entre as metodologias, na fase. 
Tabela 3. Coeficientes de digestibilidade verdadeira do fósforo dos alimentos, utilizando diferentes metodologias, para suínos em crescimento e em terminação (\%)

\begin{tabular}{|c|c|c|c|c|c|c|c|}
\hline \multirow[b]{2}{*}{ Alimento } & \multicolumn{3}{|c|}{ Crescimento } & \multicolumn{3}{|c|}{ Terminação } & \multirow[b]{2}{*}{$\begin{array}{l}\text { Médic } \\
\text { geral }\end{array}$} \\
\hline & $\begin{array}{c}\text { Coleta } \\
\text { total }\end{array}$ & $\begin{array}{c}\text { Indicador } \\
\text { fecal }\end{array}$ & $\mathrm{M} \pm \mathrm{EP}$ & $\begin{array}{c}\text { Coleta } \\
\text { total }\end{array}$ & $\begin{array}{c}\text { Indicado } \\
\mathrm{r} \text { fecal }\end{array}$ & $\mathrm{M} \pm \mathrm{EP}$ & \\
\hline $\begin{array}{l}\text { Farinha de carne e ossos } \\
35 \% \text { PB }(7,26)^{1}\end{array}$ & 64,64 & 66,12 & $65,38 \pm 4,77$ & 59,64 & 58,70 & $59,17 \pm 4,42$ & 62,04 \\
\hline $\begin{array}{l}\text { Farinha de carne e ossos } \\
41 \% \text { PB }(7,06)^{1}\end{array}$ & 64,81 & 57,93 & $61,37 \pm 2,92$ & 68,95 & 59,97 & $64,46 \pm 2,73$ & 62,92 \\
\hline $\begin{array}{l}\text { Farinha vísceras e penas } \\
\text { de aves }(2,07)^{1}\end{array}$ & 55,13 & 54,28 & $54,71 \pm 1,84$ & 47,24 & 53,20 & $50,22 \pm 2,01$ & 52,47 \\
\hline Farinha de penas $(0,36)^{1}$ & 78,08 & 87,79 & $82,93 \pm 5,09$ & 96,78 & 100,43 & $98,60 \pm 1,47$ & 90,77 \\
\hline $\begin{array}{l}\text { Farinha de peixes } \\
(1,77)^{1}\end{array}$ & 82,27 & 88,87 & $85,57 \pm 4,91$ & 97,77 & 84,92 & $91,35 \pm 5,80$ & 88,46 \\
\hline Soro de leite $(0,62)^{1}$ & 90,25 & 92,23 & $91,24 \pm 3,06$ & 81,35 & 104,24 & $92,79 \pm 5,95$ & 92,02 \\
\hline Média método $\pm \mathrm{EP}^{2}$ & $\begin{array}{c}72,53 \pm \\
2,58 \mathrm{a}\end{array}$ & $\begin{array}{c}74,54 \pm \\
3,20 \mathrm{a}\end{array}$ & & $\begin{array}{c}75,29 \pm \\
3,59 \mathrm{a}\end{array}$ & $\begin{array}{c}76,91 \pm \\
3,89 \mathrm{a} \\
\end{array}$ & & \\
\hline
\end{tabular}

Coeficiente de variação $=12,8 \%$. Médias com letras distintas na linha diferem entre si pelo teste Newman-Keul's $(\mathrm{P}>0,05)$.

$\mathrm{M} \pm \mathrm{EP}$ : Média \pm erro-padrão da média. ${ }^{1}$ Conteúdo de fósforo analisado; ${ }^{2}$ Comparação de médias entre as metodologias, na fase.

A farinha de penas apresentou valores de CDAP e CDVP do fósforo de $72,3 \%$ e $90,8 \%$, respectivamente. $\mathrm{O}$ coeficiente de digestibilidade aparente foi semelhante ao indicado em Veevoedertabel... (1998), que corresponde a $75,0 \%$, valor médio determinado em animais de crescimento e terminação. Estes altos valores podem indicar que, apesar do conteúdo relativamente baixo de fósforo $(0,32 \%)$, um processamento eficiente na fabricação desse alimento pode ter contribuído para aumentar a digestibilidade do fósforo neste alimento.

Os valores mais baixos do CDAP e do CDVP encontrados entre os alimentos avaliados foram da farinha de vísceras e penas de aves, 49,0 e $52,5 \%$, respectivamente. Estes resultados foram inferiores ao apresentado por Waldroup et al. (1965), que encontraram coeficientes de disponibilidade do fósforo de $100 \%$ na farinha composta por resíduos de abatedouros de aves. Vale salientar que não existem grandes diferenças entre valores de digestibilidade e disponibilidade em fontes de fósforo inorgânico (Jongbloed e Kemme, 1998).

Em se tratando da farinha de penas, mesmo com os altos valores de CDAP e CDVP encontrados, 52,5 e $90,8 \%$, respectivamente, a mistura de maior quantidade de matéria orgânica ao produto final, no caso da farinha de penas e vísceras, sobretudo de sangue e seus resíduos, bem como sua influência direta nas reações de processamento do alimento, poderia servir de justificativa para o menor valor de digestibilidade do fósforo encontrado no alimento contendo vísceras.

A farinha de peixe apresentou o maior valor de coeficiente de digestibilidade aparente entre os alimentos avaliados, que foi de 85,5\%. Este resultado está semelhante ao achado por Jongbloed e Kemme (1998) e é mais alto que o verificado por Sauvant et al. (2003), de 84,0 e $77,0 \%$, respectivamente. O CDVP obtido, $88,5 \%$, não diferiu do CDAP. A farinha de peixe apresentou alta digestibilidade para o fósforo, semelhante à digestibilidade de outros nutrientes, que também se apresentam mais altos quando comparados a outros produtos de origem animal, como as farinhas de carne e ossos.

Entre os alimentos avaliados, o que apresentou os maiores coeficientes de digestibilidade aparente e verdadeira do fósforo foi o soro de leite em pó. Este resultado confirma os já obtidos por Jongbloed e Kemme (1998), que obtiveram maiores valores de digestibilidade e disponibilidade do fósforo em produtos lácteos. $\mathrm{O}$ valor médio do CDAP no soro de leite obtido, $80,0 \%$, foi numericamente mais baixo que os apresentados por Jongbloed e Kemme (1998) e Sauvant et al. (2003), pois ambos encontraram 90,0\%. O CVB (Veevoedertabel..., 1998) apresenta coeficiente de digestibilidade do fósforo de $82 \%$ para esse alimento. O coeficiente 
de digestibilidade verdadeira de $92,0 \%$ é semelhante aos valores apresentados por Jongbloed e Kemme (1998) e Sauvant et al. (2003).

Com relação aos produtos de origem animal, existem variações entre os diferentes produtos e entre o mesmo produto em diferentes partidas, diferenças que podem ser atribuídas à matéria prima original, à composição, ao processamento e à estrutura física (granulometria) nos quais se apresentam (Jongbloed e Kemme, 1998).

O conteúdo de fósforo total e digestível verdadeiro dos alimentos de origem animal, para suínos nas fases de crescimento e terminação, encontra-se na Tab. 4.

Tabela 4. Conteúdo de fósforo total (P total) e digestível (Pd) verdadeiro dos alimentos de origem animal nas fases de crescimento e terminação (\%)

\begin{tabular}{lccc}
\hline & P total & Pd crescimento & Pd terminação \\
\hline Farinha de carne e ossos 35 & 6,58 & 4,30 & 3,89 \\
Farinha de carne e ossos 41 & 6,45 & 3,96 & 4,16 \\
F. de vísceras e penas de aves & 1,87 & 1,02 & 0,94 \\
Farinha de penas & 0,32 & 0,27 & 0,31 \\
Farinha de peixe 55 & 1,61 & 1,38 & 1,47 \\
Soro de leite & 0,59 & 0,54 & 0,55 \\
\hline
\end{tabular}

Valores expressos na matéria natural.

\section{CONCLUSÕES}

Não houve diferenças na determinação da digestibilidade aparente e verdadeira do fósforo pela metodologia de coleta total de fezes e do indicador fecal $\left(\mathrm{Cr}_{2} \mathrm{O}_{3}\right)$, desse modo, ambas podem ser utilizadas para determinação desses valores. Também não foram verificadas diferenças no aproveitamento desse mineral entre suínos nas fases de crescimento e terminação, assim, podem ser utilizados valores médios de coeficientes de digestibilidade verdadeiro entre as duas fases na formulação de rações com base no conteúdo de fósforo digestível.

\section{REFERÊNCIAS BIBLIOGRÁFICAS}

BÜNZEN, S.; ROSTAGNO, H.S.; LOPES, D.C. et al. Digestibilidade do fósforo de alimentos de origem vegetal determinada com suínos em crescimento e terminação. Rev. Bras. Zootec., v.37, p.1236-1242, 2008.

DELLAERT, B.M.; VAN DER PEET, G.F.V.; JONGBLOED, A.W. et al. A comparison of different techniques to assess biological availability of feed phosphates in pig feeding. Neth. J. Agric. Sci., v.38, p.555-566, 1990.

GOMES, P.C.; ROSTAGNO, H.S.; COSTA, P.M.A. et al. Digestibilidade aparente e verdadeira do fósforo de cinco alimentos, determinada em suínos de diferentes idades. Rev. Bras. Zootec., v.18, p.77-90, 1989.
JONGBLOED, A.W.; KEMME, P.A. Apparent digestible phosphorus in the feeding of pigs in relation to availability, requirement and environment. Digestible phosphorus in feedstuffs from plant and animal origin. Neth. J. Agric. Sci., v.38, p.567-575, 1990.

JONGBLOED, A.W.; KEMME, P.A. Disponibilidad del fosforo en ingredientes alimenticios para ganado porcino. Anaporc, n. 175, p.26-39, 1998.

MOREIRA, J.A.; VITTI, D.M.S.S.; LOPES, J.B. et al. Cinética do fósforo em tecidos de suínos alimentados com dietas contendo enzima fitase. Arq. Bras. Med. Vet. Zootec., v.56, p.74-80, 2004.

ROSTAGNO, H.S.; FEATHERSTON, W.R. Estudos de métodos para determinação de disponibilidade de aminoácidos. Rev. Bras. Zootec., v.6, p.64-75, 1977.

ROSTAGNO, H.S.; ALBINO, L.F.T.; DONZELE, J.L. Tabelas brasileiras para aves $e$ suínos. composição de alimentos e exigências nutricionais. Viçosa: UFV, 2000. 141p.

SAUVANT, D.; PEREZ, J.M.; TRAN, G. Tablas de composición y de valor nutritivo de las matérias primas destinadas a los animales de interés ganadero. Paris: INRA, 2003. (versão espanhola). 
SILVA, D.J.; QUEIROZ, A.C. Análise de alimentos (métodos químicos e biológicos). 3.ed. Viçosa: UFV, 2004. 235p.

SISTEMA de análises estatísticas e genéticas SAEG. Versão 8.0. Viçosa: UFV, 2001. 142p.

TRAYLOR, S.L.; CROMWELL， G.L.; LINDEMANN, M.D. Bioavailability of phosphorus in meat and bone meal for swine. $J$. Anim. Sci., v.83, p.1054-106, 2005.
PEKAS, J.C. Versatible swine labotarory apparatus for physiologic and metabolic studies. J. Anim. Sci., v.2, p.1303-1306, 1968.

VEEVOEDERTABEL: Gegevens over chemische samenstelling, verteerbaarheid envoederwaarde van voedermiddelen. Lelystad: Centraal Veevoeder Bureau, 1998.

WALDROUP, P.W.; AMMERMAN, C.B.; HARMS, R.H. The utilization of phosphorus from animal protein sources for chicks. Poult. Sci., v.46, p.659, 1965. 